DOI: https://doi.org/10.46296/ig.v3i6.0015

\title{
PROCESOS DE OBTENCIÓN DEL LICOR DE PÉTALOS DE ROSAS
}

\section{PROCESSES FOR OBTAINING ROSA PETAL LIQUOR}

\author{
Mendoza-Pico Vicky ${ }^{1 *}$ \\ ${ }^{1}$ Universidad de Jaén, UJA. Jaén, España. \\ *Correo: vmendoza8924@gmail.com
}

\begin{abstract}
Resumen
El presente trabajo de investigación es una revisión bibliográfica enfocada en la obtención de licor con características específicas, las cuales se deben a la presencia de un aceite esencial proveniente de los pétalos de rosas, estos pétalos son considerados como rechazo de la industria florícola y su destino final es el compostaje. El aprovechamiento de este subproducto radica en que el aceite esencial logra modificar el sabor y color del licor elaborado, dándole un valor agregado al producto final. Para elaborar una bebida alcohólica se consideran varios procesos que pueden variar dependiendo de la materia prima que se utilice, los cuales pueden ser maceración, arrastre de vapor, extracción sólido-liquido, entre otros; además se evidencia que los licores suelen producirse con sustancias adicionales y entre ellas se encuentran flores como: rosa, lavanda, azafrán, que son consideradas como el ingrediente principal. Debido a que en Ecuador el $80 \%$ de la industria florícola pertenece a plantaciones de rosas que en su mayoría son destinadas a la exportación, generando residuos que son utilizados como compostaje; el proceso más adecuado para llevar a cabo este producto es la extracción sólido-líquido a temperatura ambiente con etanol como solvente, esto se debe a que el etanol es parte de la composición del producto final y además mantiene las propiedades características del aceite esencial que se extrae de los pétalos de rosas.
\end{abstract}

Palabras clave: rosa, extracción, sólido-líquido, destilación, licores.

\begin{abstract}
This research work is a bibliographic review focused on obtaining liquor with specific characteristics, which are due to the presence of an essential oil from rose petals, these petals are considered as rejection of the flower industry and its final destination is composting. The use of this by-product lies in the fact that the essential oil manages to modify the flavor and color of the elaborated liquor, giving added value to the final product. To elaborate an alcoholic beverage several processes are considered that can vary depending on the raw material used, these processes can be maceration, steam entrainment, solid-liquid extraction, among others; It is also evident that liqueurs are usually produced with additional substances and among them are flowers such as: rose, lavender, saffron, which are considered the main ingredient. Because in Ecuador $80 \%$ of the flower industry belongs to rose plantations that are mostly destined for export, generating waste that is used as composting. The most suitable process for carrying out this product is solid-liquid extraction at room temperature with ethanol as a solvent, this is because ethanol is part of the composition of the final product and also maintains the characteristic properties of the essential oil that is extract from the rose petals.
\end{abstract}

Keywords: rose, extraction, solid-liquid, distillation, liqueurs.

Información del manuscrito:

Fecha de recepción: 06 de abril de 2020

Fecha de aceptación: 29 de junio de 2020

Fecha de publicación: 10 de julio de 2020 


\section{Introducción}

Las bebidas alcohólicas son parte de las costumbres y tradiciones de zonas urbanas y rurales del Ecuador, además, están vinculadas a su práctica de vivir y convivir en la cotidianidad, puesto que son parte sustancial del interrelacionamiento festivo, ceremonial y estimulante de los grupos sociales (Romero, 2013).

Un licor con sabor y olor característico de sustancias ajenas a la bebida alcohólica, puede generar un componente innovador que cambiaría las expectativas y gustos de los consumidores. En la Universidad Central del Ecuador se encontraron dos trabajos de producción de licor; uno realizado en 2006 acerca de un licor con cortezas de mandarina y otro en 2008 para un licor elaborado con pulpa de guayaba. A nivel internacional se encontró una solicitud de patente proveniente de la India para producir una bebida con rosas de bajo contenido alcohólico mediante fermentación (Valencia, 2012).

En el Ecuador, la industria florícola se ha desarrollado de manera acelerada, puesto que se maneja de forma totalmente independiente y se considera un sector de gran rentabilidad. La rosa es la flor más importante en casi todos los mercados del mundo, en nuestro país se producen diferentes tipos de flores, entre las cuales se encuentran las rosas, con más de 300 variedades entre rojas y de colores, convirtiéndose en el país con el mayor número de hectáreas cultivadas y produciendo la gama más variada de colores (Peña, 2010).

Dado que en la industria florícola existen flores que se consideran como de desecho, debido a que no cumplen con los estándares de calidad para ser vendidas como producto principal, se considera que es posible darle un valor agregado a este residuo. Un licor a base de pétalos de rosas puede ser una potencial opción de innovación y cambio. Su proceso es realizado de distintas maneras según fuentes bibliográficas que van desde la maceración de las rosas hasta una extracción sólido-líquido a temperatura ambiente y con poca agitación, para así obtener un producto con características organolépticas agradables.

Mediante este estudio se pretende obtener de manera bibliográfica la 
información necesaria para llevar a cabo el proceso productivo de un licor de rosas, analizando la información que se encuentra en revistas y documentos científicos.

\section{Producción nacional de rosas en el Ecuador}

En lo que respecta al sector florícola ecuatoriano es considerado uno de los sectores productivos de mayor crecimiento dentro de la economía, de modo que ha aumentado desde el $15,8 \%$ hasta el $57,6 \%$ del total de las exportaciones no tradiciones del país (Expoflores, 2013).

Para el 2012, el Ecuador contaba con un total de 571 haciendas productoras de flores, las cuales totalizaban unas 4000 hectáreas en 13 provincias: Carchi, Imbabura, Pichincha, Cotopaxi, Tungurahua, Chimborazo, Cañar, Azuay, Esmeraldas, Santo Domingo de Los Tsáchilas, Guayas, Los Ríos y Santa Elena (Banco Central, 2012). En Ecuador se cultivan diferentes variedades de flores, como las rosas con 300 o más modelos de colores, convirtiéndose en un país con gran número de hectáreas cultivadas y produciendo la gama más variada de colores, de forma que las rosas son uno de los principales productos de exportación (Gómez, 2014).

\section{Aceite esencial}

Los aceites esenciales no son compuestos puros sino mezclas con multitud de sustancias que se encuentran en distintas proporciones y que en conjunto proporcionan al aceite esencial sus características propias (Ortuño, 2006). Los aceites esenciales están contenidos en glándulas o vesículas secretoras inmersas en los tejidos de las hojas, flores, corteza (pericarpio) y semillas de los frutos de muchas especies (Dabbah et al., 1970). El hombre desde la antigüedad ha usado sustancias naturales extraídas de las plantas, como los aceites esenciales, para combatir enfermedades y preservar alimentos. Hoy en día, estas sustancias han perdido su uso debido a la aparición de sustancias sintéticas, no obstante, tienen la ventaja de que no representan un peligro para la vida y salud humana (Hersom, 1974).

\subsection{Métodos de obtención de aceite esenciales}

La obtención del aceite esencial puede variar en dependencia de la 
materia prima a la que se le aplique la extracción.

\section{- Destilación con arrastre de vapor}

Se denomina hidrodestilación a la destilación de las flores y otras partes de la plata por medio de vapor de agua. El vapor de agua arrastra el aceite esencial que contienen las flores. En realidad, los aceites esenciales tienen un punto de ebullición superior al del agua, pero la mezcla de aceite esencial-agua presenta un punto de ebullición inferior y por eso puede ser destilada (Ortuño, 2006). La destilación por arrastre de vapor es un método sencillo y de bajo costo, aunque su inconveniente se debe a que requiere largos períodos de operación y tiene rendimientos bajos en comparación con otros métodos (Sefidkon et al., 2006).

\section{- Extracción con disolventes}

La extracción con disolventes es un modo más moderno que el anterior para la obtención de aceites esenciales. En este método se engloban muchos procedimientos diferentes que incluyen la utilización de distintos tipos de disolventes, desde los clásicos derivados del petróleo hasta la reciente utilización de $\mathrm{CO}_{2}$ líquido, ya en aplicación industrial por parte de algunas industrias (Ortuño, 2006). Martínez (2003) hace referencia a la extracción con disolventes, donde menciona que esta técnica es utilizada solo a escala de laboratorio ya que al momento de usarla a nivel industrial resulta muy costoso por el valor comercial de los disolventes, porque se obtiene un producto contaminado con otras sustancias y además por el riesgo de explosión e incendio característico de muchos disolventes orgánicos volátiles.

\section{La industria del licor}

El licor es una bebida hidroalcohólica aromatizada, obtenida por maceración, infusión o destilación de diversas sustancias vegetales naturales, con alcoholes destilados aromatizados o por adiciones de extractos, esencias 0 aromas autorizados con una generosa proporción de azúcar. Se caracteriza por un contenido alcohólico superior a los $15^{\circ}$, llegando en algunos casos a superar los $50^{\circ}$ centesimales, diferenciándose de los aguardientes por mayor o menor contenido de azúcar (Ramírez, 2010). 


\subsection{Tipos de licor}

De acuerdo con lo establecido en la Norma INEN 1837: Bebidas Alcohólicas. Licores, se especifica la siguiente clasificación (INEN, 2016).

\section{- Licor seco}

Este producto contiene menos de 10 g/L de azúcares.

\section{- Licor semiseco}

Es el producto cuyo contenido de azúcares está comprendido entre 10 y $50 \mathrm{~g} / \mathrm{L}$.

\section{- Licor dulce}

Este producto presenta una concentración de azúcares entre 50 y $250 \mathrm{~g} / \mathrm{L}$.

\section{- Licor crema}

Es un producto de consistencia viscosa que contiene más de $250 \mathrm{~g} / \mathrm{L}$ de azúcares.

\section{- Licor escarchado}

Es el producto sobresaturado de azúcar. Además, la norma INEN establece disposiciones y requisitos para que una bebida alcohólica pueda ser considerada como licor.

Disposiciones generales. LoS licores pueden prepararse con sustancias aromáticas y/o edulcorantes permitidos. Además, no deben contener sustancias empleadas comúnmente como desnaturalizantes de alcoholes ni ácidos minerales u orgánicos extraños a la composición normal del producto. Asimismo, no deben prepararse con esencias, extractos, mezclas aromáticas, materias colorantes, edulcorantes artificiales y conservantes de uso regulado.

El agua que se utiliza con fines de hidratar el producto hasta los niveles establecidos en la Norma INEN, podrá ser desmineralizada, desionizada o destilada.

Requisitos. Los licores pueden ser transparentes 0 coloreados de acuerdo con las características de sus componenentes. Deben tener las características organolépticas propias de sus ingredientes.

\section{Obtención de licores}

Existen diversos mecanismos en lo que concierne a la elaboración de licores, sin embargo, no todos los métodos dan al producto resultante la misma calidad.

Digestión. Se utiliza para extraer las sustancias aromáticas y gustativas de los vegetales utilizados, por medio del calor. Las materias se 
colocan en un alambique con alcohol diluido y a una temperatura de 50 $60^{\circ} \mathrm{C}$.

Destilación. Es el proceso que se sigue para conseguir los distintos tipos de aguardientes. Esta operación tiene la ventaja de separar las fracciones de los vapores condensados en el refrigerador 0 serpentín. Tanto si se destilan directamente las materias del compuesto como si se destila el resultado de una maceración, este método da al licor una elevada calidad.

\section{Maceración o extracción sólido-}

líquido. Consiste en introducir las materias vegetales en un baño de alcohol o de líquidos alcohólicos. De este modo, los vegetales inmersos ceden al alcohol todos los componentes aromáticos solubles que contienen. Posteriormente, el producto se somete 0 no a destilación. El proceso puede extenderse desde unas horas a más de un mes.

Los licores de mejores características son, generalmente, los que proceden de una destilación, con maceración previa. Los procedimientos de elaboración de los licores clásicos se diferencian de los que se producen de forma industrial (Reyes-Linares et al., 2011).

Según Aleixandre (1999) en su investigación sobre los aspectos generales de la elaboración de licor de limón, los licores industriales se fabrican mediante la disolución en frío de aceites esenciales, puros 0 mezclas de estos en alcohol. También se utilizan para la fabricación los extractos de esencias. Según este método, se disuelven en alcohol esencias de aceites, destilados especiales para licores y sustancias básicas, que contienen todos los ingredientes necesarios para la elaboración de un licor, como colorantes, ácidos y aromas.

Un estudio realizado por Romero (2013) describe la maceración como proceso principal para la obtención de 12 licores de distintos productos que van desde el maracuyá hasta el jengibre, el autor menciona que utiliza vodka de $40^{\circ}$ como solvente de la extracción. Por otra parte, Valencia (2012) en su investigación acerca del aprovechamiento de pétalos de rosas para la producción de licor, detalla que su proceso de obtención está basado en varias 
etapas, como la extracción con vapor de agua de donde obtiene el aceite esencial, posteriormente realiza un mezclado con etanol que lo somete a una extracción sólido-líquido en un lecho estático por un período de 4 a 6 semanas y finaliza el proceso con una filtración y clarificación del licor. Un proceso similar ha sido reportado en el estudio Guijarro (2013), donde se describe el mismo procedimiento para la obtención de un licor con sabor de capulí, utilizando tanto las hojas como su pulpa.

Debido a la gran cantidad de pétalos de rosas que no se utilizan en la industria florícola por no cumplir con las normas de calidad para su uso principal y que son considerados como un residuo del producto final, se evidencia que es necesario darle un valor agregado a este resido, extrayendo el aceite esencial que contienen los pétalos de las rosas para utilizarlo y producir un licor que posea un olor y sabor característico a las rosas, esto se da gracias a las propiedades que le confiere el aceite esencial extraído de los pétalos.

Para producir el licor de rosas se necesita obtener el aceite esencial en primera instancia, para posteriormente mezclarlo con el alcohol. Si bien es cierto la maceración es un proceso muy utilizado al momento de la preparación de los distintos licores, no obstante, cuando nos referimos a un licor de rosas tenemos que tener en cuenta ciertos criterios, como por ejemplo, los pétalos de rosas que se usan son un desecho de la industria florícola, lo que significa que en su proceso de obtención las flores pudieron haber sido contaminadas con algún pesticida, esto representaría que en un proceso de extracción convencional se arrastren las sustancias tóxicas presentes en los pesticidas. Otro punto de vista es que en la maceración se pueden producir sustancias no deseadas como el metanol. Por lo anteriormente mencionado es recomendable utilizar una de las técnicas de extracción sólido-líquido, donde la materia prima tenga contacto indirecto con el solvente utilizado y no sea de larga duración como sucede en la maceración, lo que evitaría la formación de metanol y el arrastre de compuestos no deseados.

\section{Conclusiones}

La industria florícola en el Ecuador ha surgido a través de los años hasta 
posicionarse como una de las principales industrias del país, es así como representa una gran fuente de ingresos debido a las exportaciones que se realizan y a las ventas locales. El aceite esencial que se encuentra en las plantas ha sido ampliamente utilizado en el mundo, por su aprovechamiento en la alimentación y preservación de los alimentos.

Los licores se pueden obtener por medio de técnicas como la maceración, digestión y destilación, siendo esta última la que mejores características confiere a los licores. La obtención de un licor de rosas es una alternativa novedosa para el aprovechamiento del residuo de la industria florícola, de manera que una extracción sólido-líquido permite extraer aceites esenciales aplicando solventes disponibles en el medio, como el etanol.

\section{Bibliografía}

Aleixandre, J. (1999). Licores. En: Vinos y bebidas alcohólicas. Dpto. de tecnología de alimentos. Universidad Politécnica de Valencia, España. Servicios de publicaciones.
Banco Central del Ecuador. (2012). Boletines estadísticos. Obtenido de: www.bce.fin.ec

Dabbah, R., Edwards, V. M., \& Moats, W. A. (1970). Antimicrobial action of some citrus fruit oils on selected food-borne bacteria. Appl. Environ. Microbiol., 19(1), 2731.

Expoflores (2013, 13 de enero). www.expoflore.com.

Recuperado el 2013, de www.expoflores.com/estadisti cas

Gómez, C. (2014). Análisis histórico del sector florícola en el Ecuador y estudio del mercado para determinar su situación actual (Bachelor's thesis, Universidad San Francisco de Quito). Quito: Ecuador. http://repositorio.usfq.edu.ec/ bitstream/23000/3323/1/1109 52.pdf

Guijarro, M. (2013). Diseño de un proceso para producir un licor con sabor a capulí. Tesis de Grado para la obtención del Título de Ingeniero Químico. Carrera de Ingeniería Química. Quito: Universidad Central del Ecuador. 65 p. http://www.dspace.uce.edu.e c/handle/25000/2294

Hersom, A. \& Hulland, E. (1974). Conservas Alimenticias. Zaragoza, España: Editorial Acribia S.A. pp. 61-62. 
INEN. (2016). NTE INEN 1837. Bebidas alcohólicas.

Requisitos. Disponible en: https://181.112.149.204/buzo n/normas/nte_inen_18372.pdf

Martínez, A. (2003). Aceites esenciales. J. Nat. Prod, 59(1), 77-79.

Ortuño, M. (2006). Manual práctico de aceites esenciales, aromas y perfumes. Madrid: Aiyana ediciones.

https://books.google.com.pr/b ooks?id=cW5TsDKqx9wC\&pr intsec=frontcover $\# v=$ onepage $\& q \& f=f a l s e$

Peña, J. (2010). Establecimiento de una plantación de una hectárea de rosas. Trabajo de graduación. Universidad de Cuenca, Cuenca, Ecuador. http://dspace.ucuenca.edu.ec /bitstream/123456789/3081/1 /tm4a44.pdf

Ramírez, E. (2010). Los Licores, origen, definición y tipos.

Reyes-Linares, A., Pino-Alea, J., \& Moreira-Ocanto, V. (2011). Aspectos generales sobre la elaboración del licor de limón. ICIDCA. Sobre los Derivados de la Caña de Azúcar, 45(1), 13-19.
Romero, C. (2013). Elaboración de macerados y mistelas con especies vegetales disponibles en la provincia del Azuay. Trabajo de graduación. Universidad de Cuenca, Cuenca, Ecuador. https://dspace.ucuenca.edu.e c/bitstream/123456789/3697/ 1/Tesis.pdf

Sefidkon, F., Abbasi, K., \& Bakhshi, G. (2006). Influence of drying and extraction methods on yield and chemical composition of the essential oil of Satureja hortensis. Food chemistry, 99(1), 19-23. https://doi.org/10.1016/j.foodc hem.2005.07.026

Valencia, M. (2012). Aprovechamiento de pétalos de rosa comestible para la producción de licor. Trabajo de Graduación previo la obtención del Título de Ingeniera Química. Carrera de Ingeniería Química. Quito: Universidad Central del Ecuador. 48

p. http://www.dspace.uce.edu.e c/handle/25000/859 